Cancer Immunol Immunother (1992) 35: 365-372

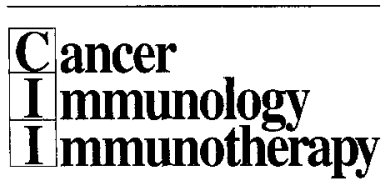

C Springer-Verlag 1992

\title{
Quantitative autoradiographic evaluation of the influence of protein dose on monoclonal antibody distribution in human ovarian adenocarcinoma xenografts
}

\author{
Farley E. Yang, Raya S. Brown, Ken F. Koral, Anaira C. Clavo, Gayle A. Jackson, and Richard L. Wahl \\ University of Michigan Medical Center, Department of Internal Medicine, Division of Nuclear Medicine, 1500 E. Medical Center Drive, \\ Ann Arbor, MI 48 109-0028, USA
}

Received 25 November 1991/Accepted 23 June 1992

\begin{abstract}
Summary. We studied the effect of monoclonal antibody protein dose on the uniformity of radioiodinated antibody distribution within tumor masses using quantitative autoradiography. Groups ( $n=11-13$ /group) of athymic nude mice with subcutaneous HTB77 human ovarian carcinoma xenografts were injected intraperitoneally with an 125I-labeled anticarcinoma-associated antigen murine monoclonal antibody, 5G6.4, using a high or a low protein dose $(500 \mu \mathrm{g}$ or $5 \mu \mathrm{g})$. At 6 days post-injection the macroscopic and microscopic intratumoral biodistribution of radiolabeled antibody was determined. The degree of heterogeneity of the labeled antibody distribution within each tumor was quantified and expressed as the coefficient of variation (CV) of the activity levels in serial histological sections. Tumors from mice given the $500-\mu \mathrm{g}$ protein doses had substantially lower CV values, $0.327 \pm 0.027$, than did tumors from animals given $5-\mu \mathrm{g}$ protein doses, $0.458 \pm 0.041,(P=0.0078)$, indicating that the higher protein dose resulted in more homogeneous distribution of radioactivity in tumors than did the lower dose. While the percentage of the injected dose reaching the tumor was comparable between groups, injecting the higher dose of protein resulted in significantly lower tumor to non-tumor uptake ratios than those obtained for the lower protein dose. These data indicate, in this system, that to achieve more uniform intratumoral antibody (and radiation for radioimmunotherapy) delivery, a relatively high protein dose must be administered. However, to obtain this increased uniformity, a substantial drop in tumor/background uptake ratios was seen. Quantitative autoradiographic evaluation of human tumor xenografts is a useful method to assess the intratumoral distribution of antibodies.
\end{abstract}

Key words: Monoclonal antibody - Ovarian carcinoma Radiolabeled compounds - Quantitative autoradiography

\section{Introduction}

Monoclonal antibodies as carriers of radionuclides, drugs, and toxins are being intensively investigated for their use in both cancer imaging and therapy [27]. Maximal antibody delivery to tumors with minimal uptake in normal tissues is desirable for both imaging and therapy. For antibody conjugate therapy, however, the uniformity of antibody distribution within the tumor mass itself is an additional concern. A homogeneous intratumoral distribution is desirable and probably necessary for many therapeutic applications. This is because even though an appropriately labeled antibody may be lethal to all cancer cells it binds to, if its delivered toxicity is unable to reach all regions within a tumor mass, some cells may survive and continue to grow. With radioimmunotherapy, the use of higher-energy $\beta$ emitters such as $90 \mathrm{Y}$ may allow for successful tumor treatment despite an inhomogeneous distribution because the emitted particles travel a substantial distance, but for lower-energy $\beta$ and $\alpha$ emitters, drugs, and toxins, adequate delivery of antibody to most or all cells in a tumor is probably obligatory for successful treatment [10].

The distribution of monoclonal antibodies within tumors may be affected by numerous biological factors that influence the accessibility of antibodies to antigenic sites (e. g. tumor blood flow, tumor vascularity, vascular permeability, antibody molecular mass, antigen, antibody affinity and tumor interstitial pressure) $[8,12,13,15,18,22]$. It has been reported that higher antibody uptake and a more uniform distribution across tumor masses was achieved when the tumor was incubated with antibody in vitro than following systemic administration in vivo. These results indicate that, in vivo, the antigenic sites are commonly not fully saturated [23]. One potential method to improve antibody delivery to the tumor antigenic sites is to administer higher levels of antibody protein so that antibody might diffuse more deeply into tumors. Some reports indicate that antibody protein dose does not have a significant effect upon the percentage of the injected dose of iodinated antibody reaching either the tumor xenografts or normal tissues in cancer models $[24,30]$. However, when an $111 \mathrm{In}$ - 
labeled anti-carcinoembryonic (CEA) antigen monoclonal antibody is used in patients, an increase in the accumulation of activity in the tumor relative to the background levels has been seen when the protein dose was increased [20]. Others have shown, in an animal model of colon cancer, that an anti-(colorectal cancer) monoclonal antibody, given at high protein doses, targets less well than at a lower protein dose, probably because of antibody saturation of tumor antigenic sites [6]. Thus, some variability of the effect of protein is present, depending on the system studied.

The effects of the protein dose on the distribution of radioantibody within the tumor itself have not been previously studied quantitatively. Initial qualitative autoradiographic techniques have, however, detected concentrations of radioantibodies primarily in perivascular areas in tumors following intravenous antibody delivery, probably because of the binding of high-affinity antibody [5]. Recently, qualitative immunohistochemical studies have demonstrated that a more uniform intratumoral distribution of antibody has been achieved with a higher administered antibody protein dose in animal studies [19]. In addition, using qualitative autoradiographic techniques, Blumenthal et al. were able to demonstrate that, for two specific antibodies to CEA that demonstrated good targeting, the intratumoral antibody distribution following i.v. administration appeared to be more uniform at high, rather than low, protein doses in a colon cancer xenograft system.

We evaluated the effect of antibody protein dose on the delivery and distribution of radioactivity within ovarian adenocarcinoma masses, studied with a radioiodinated anticarcinoma monoclonal antibody, 5G6.4 [31], injected into nude mice bearing subcutaneous human ovarian carcinoma xenografts. Whole-body and intratumoral distributions of the labeled antibody were digitally quantified using a computer image-analysis system. This quantitative method was developed to provide an objective means for comparing the autoradiographs obtained from the different tumors [35]. Our initial results with this method were recently reported in abstract form [34].

\section{Materials and methods}

Monoclonal antibody. $5 \mathrm{G} 6.4$ is an IgG2ak murine monoclonal antibody reactive with epithelial carcinomas [31]. It was produced in mouse ascites and purified by staphylococcal protein A column chromatography, eluting at $\mathrm{pH} 5$. Protein concentration was determined by the colorimetric method developed by Bradford using bovine $\operatorname{IgG}$ (Bio-Rad) as reference standard [3]. The purity of the $5 \mathrm{G} 6.4$ preparation was verified by sodium doclecyl sulfate/polyacrylamide gel electrophoresis under reducing conditions.

Antibody radiolabeling. The iodogen method was used to label the antibody with sodium [ $\left.{ }^{125} \mathrm{I}\right]$ iodide (ICN) [7]. The radiolabeling reaction consisted of $2.69 \mathrm{mCi}{ }^{125} \mathrm{I}$ reacted with a protein mass of $94.5 \mu \mathrm{g}$ at a concentration of $10.5 \mathrm{mg} / \mathrm{ml}$. The preparation was purified via anion-exchange chromatography (Bio-Rad AG 1-X8, 200-400 mesh). Freeiodine contamination was determined by silica gel TLC; only $2 \%$ free iodine was measured in the final preparation used for this study. Immunoreactivity was confirmed by a direct cell binding assay, which was performed with viable human ovarian carcinoma (HTB77 IP3) target

$1 \times$ dose uptake
\begin{tabular}{|c|c|c|}
\hline 1 & 2 & 3 \\
\hline 2 & 3 & 4 \\
\hline 3 & 4 & 5 \\
\hline
\end{tabular}

mean: 3

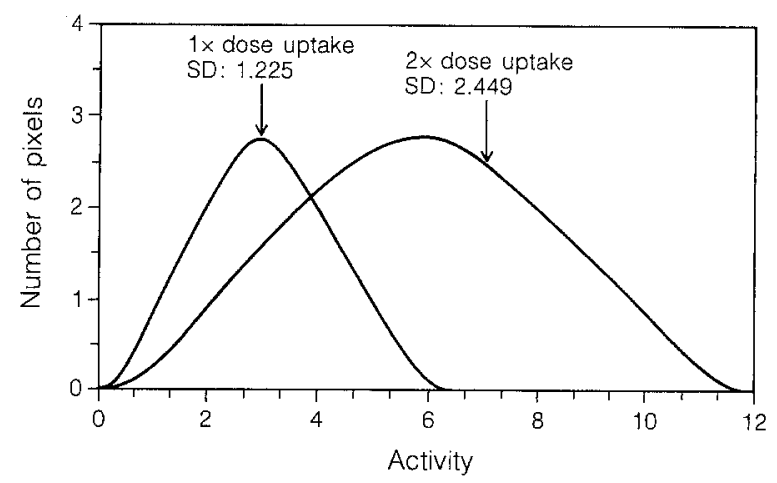

Fig. 1. Two hypothetical nine-pixel tumor sections treated with one dose or with two doses. The numbers in the squares represent the activities $(\mu \mathrm{Ci} / \mathrm{g})$ for each pixel of these sections. The distributions are identical, but the means $\pm S D$ of the uptakes are different. The coefficient of variation, calculated by dividing the standard deviation by the mean, is identical between the two "tumors" and is used as a measure of the uniformity of distribution for the different uptakes

cells under conditions of antigen excess [33]. 125I-labeled 5G6.4 demonstrated a baseline immunoreactivity of $65.1 \pm 2.3 \%$.

Animal model. Female nude mice (nu/nu) (Swiss) were injected subcutaneously with a single-cell suspension of $10 \times 10^{6}$ HTB77 IP3 human ovarian carcinoma cells. When the tumors reached at least $5 \mathrm{~mm}$ in diameter, the biodistribution studies were performed.

Biodistribution study. Intraperitoneal injections of the ${ }^{125} \mathrm{I}-5 \mathrm{G} 6.4$ were administered, taking advantage of egress of the antibody from the peritoneal cavity to the systemic circulation [32]. An initial pilot study with three groups of mice receiving dosages of 5,50 , or $500 \mu \mathrm{g} 5 \mathrm{G6.4}$ was performed to test the feasibility of the method. Subsequently, in the definitive study, the mice were divided into two groups: both groups received approximately $75 \mu \mathrm{Ci}{ }^{125} \mathrm{I}-5 \mathrm{G} 6.4$ each but at different protein doses: $5 \mu \mathrm{g}(n=11)$ and $500 \mu \mathrm{g}(n=13)$. To prepare the $500-\mu \mathrm{g}$ doses, $5 \mu \mathrm{g}$ radiolabeled antibody was mixed with $495 \mu \mathrm{g}$ unlabeled $5 \mathrm{G} 6.4$ antibody prior to injection. All mice were sacrificed 6 days after injection and tissues were weighed and counted in a gamma counter. The percentage of the injected dose per gram was calculated using standard techniques $[28,29,32]$.

Quantitative autoradiography. Excised tumors were quickly frozen at $-70^{\circ} \mathrm{C}$. Representative frozen sections of each tumor, primarily from equatorial regions, were cut at $12-\mu \mathrm{m}$ thickness at a minimum distance of $600 \mu \mathrm{m}$ from one another. Contact autoradiography was performed by exposing Kodak Xar5 film to the sections for $64 \mathrm{~h}$ at room temperature [14]. Standards correlating activity in $\mu \mathrm{Ci} / \mathrm{g}$ with film absorbance were obtained from autoradiographs of frozen sections of the livers of two $\mathrm{BALB} / \mathrm{c}$ mice injected with $100 \mu \mathrm{Ci}$ and $200 \mu \mathrm{Ci}$ of the same ${ }^{125} \mathrm{I}-5 \mathrm{G} 6.4$ preparation used in the biodistribution study. Livers were weighed, counted, frozen, and sectioned at $12 \mu \mathrm{m}$. A timed course of exposure (between $2 \mathrm{~h}$ and $128 \mathrm{~h}$ ) was used to obtain a standard gray scale correlating the activity with absorbance for each piece of film used. The film was 
a

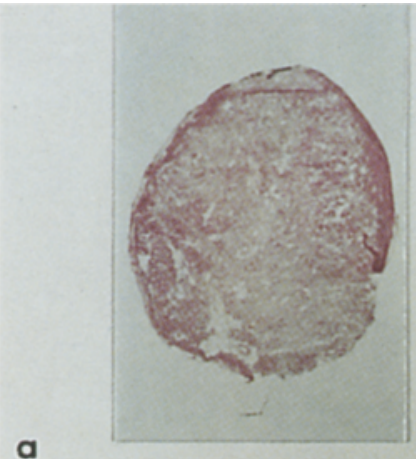

A

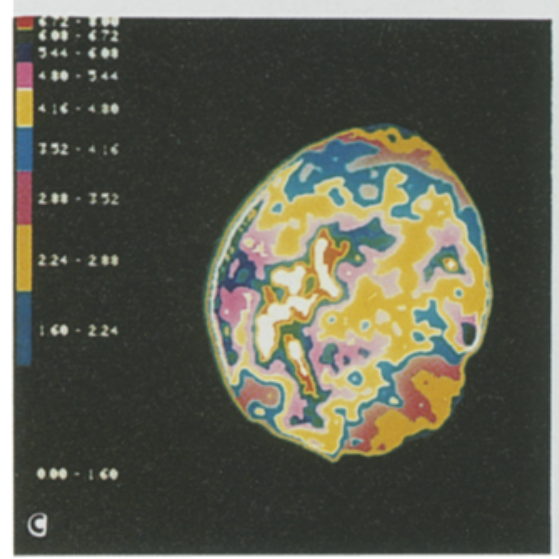

a
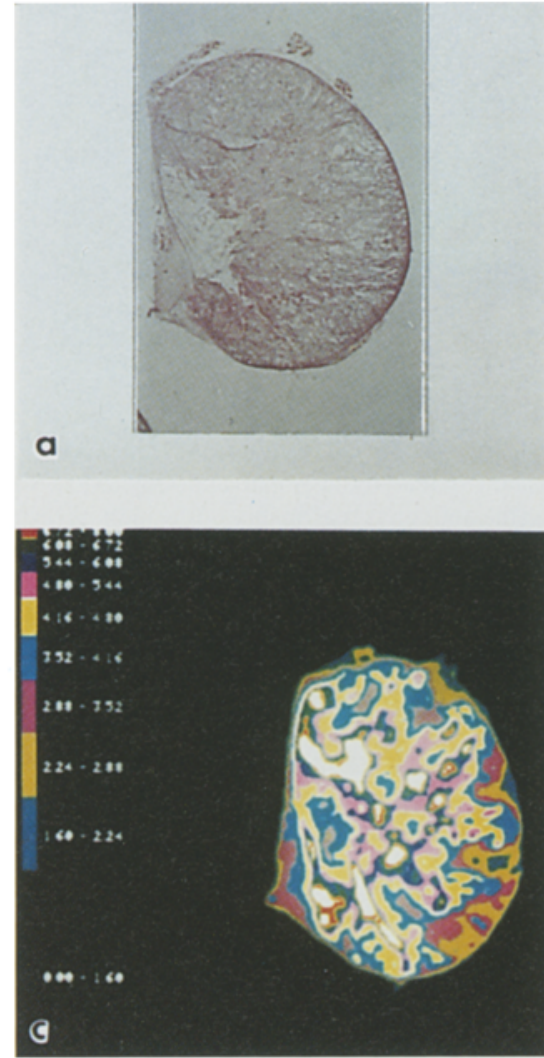

b

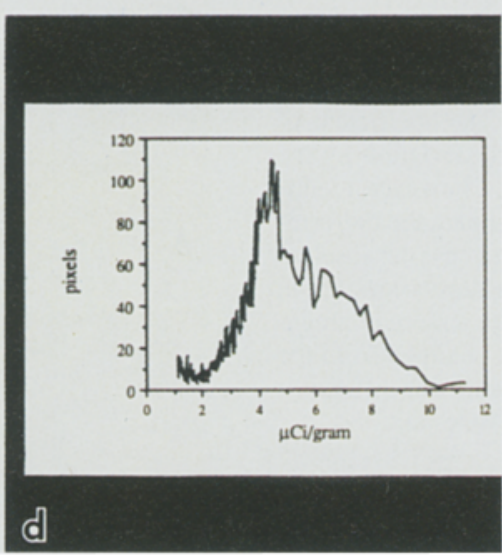

d

b

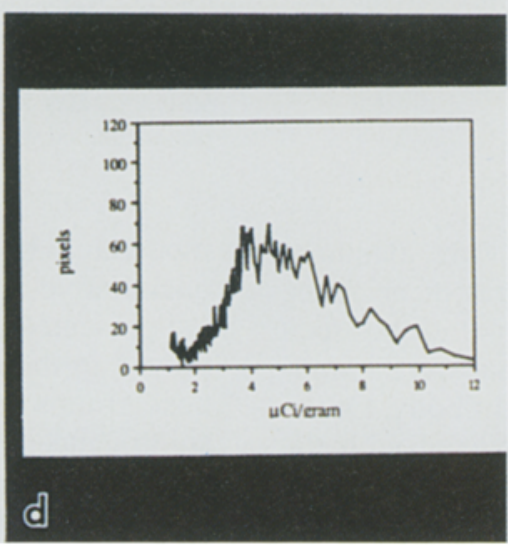

Fig. 2 A, B. Examples of the quantitative autoradiographic analysis used in this study. A A representative section from a tumor removed from a mouse that received $500 \mu \mathrm{g}{ }^{125} \mathrm{I}-5 \mathrm{G} 6.4$. The coefficient of variation for this section was 0.347 . B A section from a tumor removed from a mouse that received $5 \mu \mathrm{g}$ 125I-5G6.4. The coefficient of variation for this section was 0.504 . $a$, The section stained with hematoxylin and eosin; $b$, the autoradiograph of the same section; $c$, the image generated from the video densitometer computer system; $d$, the plot of the number of pixels in the tumor at each activity level detected by the densitometer developed by a commercial Du Pont developer. Representative sections from each tumor were stained with hematoxylin and eosin to assess the tumor architecture and degree of necrosis.

The autoradiographs of each section (mean of 11) of tumor were analyzed at the Image Analysis Facility at the University of Michigan
Medical Center. Relative absorbance was measured by an International Imaging System model 75 image processor using a Dage-MTI Newvicon camera with a $25-\mathrm{mm} 1: 1.4$ Vidicon lens. The system is connected to a Masscomp 500 dual processor 68000 based computer, which runs a real-time version of the Unix operating system. Images were digitized 
into a $512 \times 512$ array of pixels (point measurements) with 256 absorbance levels. The width of each pixel square was $155 \mu \mathrm{m}$. Prior to analysis the system was normalized to ensure that each pixel had a linear intensity/absorbance response. This was done by taking a series of images from the brightest background field that the camera analyzed (in this case a blank piece of film) to the darkest (a black field). A computer program then corrected every pixel for a linear response. Each absorbance level was then automatically converted to a specific activity level $(\mu \mathrm{Ci} / \mathrm{g})$ by comparison to the standard gray scale.

This process enabled us to assign specific radioactivity levels to every pixel in the autoradiographic images. The outline of each autoradiographic image was carefully traced so that only regions correlating to tumor were analyzed. Plots of activity level $(\mu \mathrm{Ci} / \mathrm{g})$ versus area of the cross-section (pixels) were generated for each tumor. The heterogeneity of intratumoral distribution is expressed by the standard deviation from the mean activity level. In order to compare different tumors, the coefficient of variation $(\mathrm{CV})$ of tumor uptake of radioactivity was calculated for each of them. Tumors with identical antibody distribution patterns but different overall uptakes will exhibit different mean antibody uptake percentages and differ in their standard deviations. The coefficient of variation, which is obtained by dividing the standard deviation by the mean tumor uptake of radioactivity for these tumors is, however, identi cal (0.408) (Fig. 1). Such a measure allows one to compare the uniformity of radioantibody uptake between different tumors, even if the absolute tumor uptake is substantially different. A low $\mathrm{CV}$ indicates less variation in activity of different regions in a tumor and therefore a more homogeneous intratumoral distribution. An average CV was obtained from the multiple sections obtained from each tumor in each group. The difference between the two groups was analyzed by an unpaired, one-tail $t$-test.

Immunohistochemistry. Two to three representative sections of each autoradiographed tumor were stained with hematoxylin and eosin to assess architecture and extent of necrosis. Additional HTB77 IP3 tumors were grown for immunohistochemical study in four nude mice, which were not injected in vivo with radiolabeled monoclonal antibodies. The tumors were removed and frozen in isopentane cooled by liquid nitrogen. Cross-sections, $10 \mu \mathrm{m}$ thick, from the middle of the tumors were cut in the cryostat at $-20^{\circ} \mathrm{C}$ and mounted on poly-t-lysine-coated slides. The sections were air dried and kept at $-70^{\circ} \mathrm{C}$ until stained.

Thawed sections were fixed for $10 \mathrm{~min}$ in buffered formalin (4\% in phosphate-buffered saline, PBS, pH 7.0) and were stained using a modification of the indirect immunoperoxidase method of Hsu [11]: sections were incubated with a $10 \mu \mathrm{g} / \mathrm{ml}$ solution of biotinylated 5G6.4 (ETAC method) [4] in diluent (4\% bovine serum albumin, 1\% horse serum in PBS) for $30 \mathrm{~min}$, washed with PBS and then further incubated with avidin-peroxidase conjugate for $30 \mathrm{~min}$ (Vectastain Kit, Vector). The sections were then washed with PBS and the bound antibody was visualized with diaminobenzidine and counterstained with hematoxylin. Sections incubated with the diluent alone were used as controls.

\section{Results}

On microscopic examination, the tumors were glandular (Fig. 2 A, B) and did not contain large areas of necrosis; however, scattered small necrotic foci could be seen throughout the entire tumor. All tumors that were immunostained expressed binding sites for this antibody. Of the tumor cells in the sections, $70 \%-90 \%$ reacted with the 5G6.4 antibody (Fig. 3 A, B). Stained granules were seen throughout the cytoplasm of most of the cells. In some cells, concentrations of stained granules were observed along the cell membranes (Fig. 4A, B). No staining was seen in the control sections (Figs. 3,4 ) or in the connective tissue of the positive sections (Fig. 4).

The in vivo intratumoral distribution of the labeled antibody, evaluated by quantitative autoradiography, was
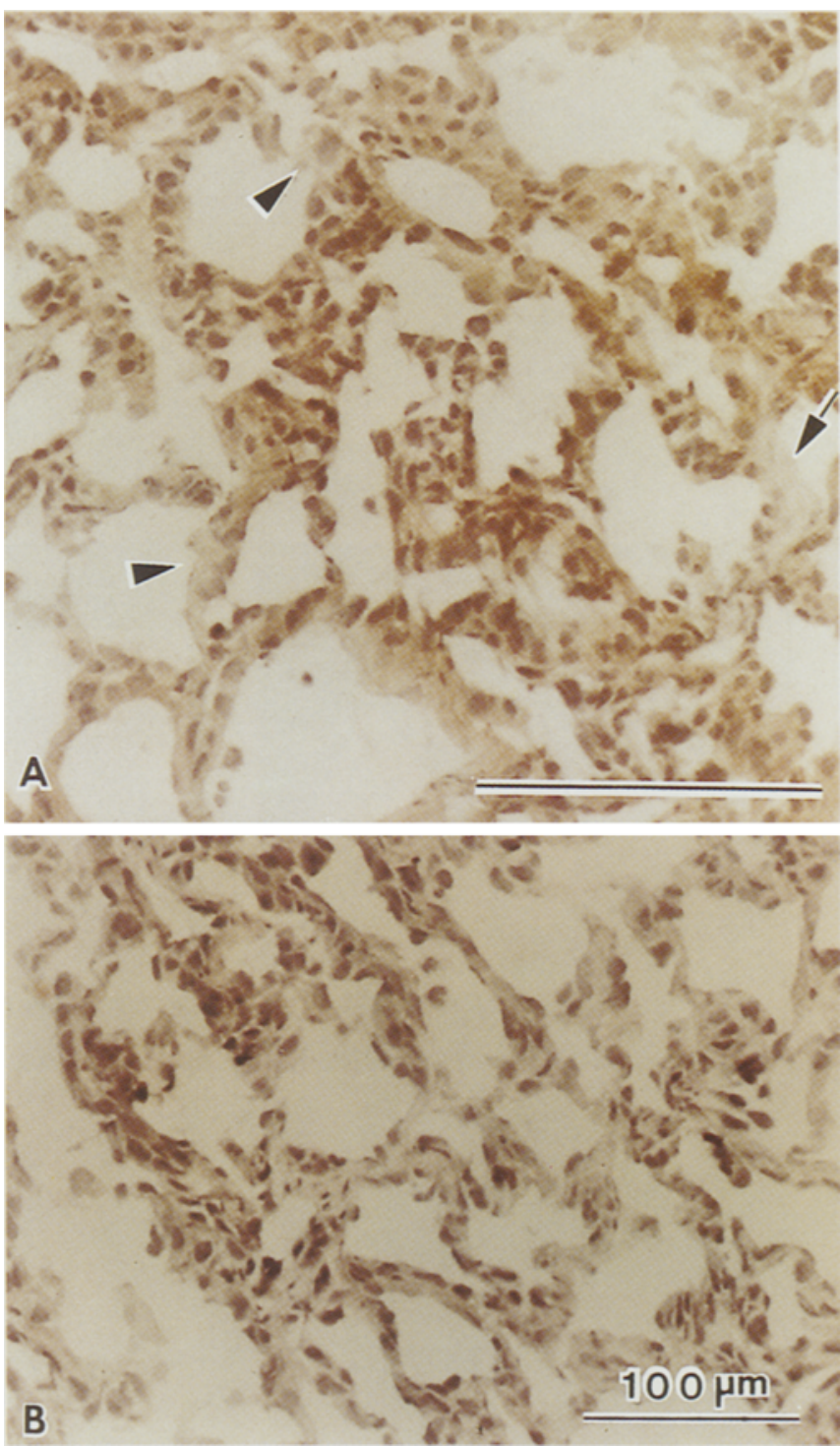

Fig. 3 A, B. Micrographs of histological sections of human ovarian carcinoma tumor xenograft grown in the nude mouse. $(200 \times)$. A Section incubated with biotinylated 5G6.4 monoclonal antibody. Most of the cells are 5G6.4-positive (the antigen is reasonably uniform in its distribution). Some cells (arrowheads) and the connective tissue (arrow) are 5G6.4-negative. The lumens do not contain 5G6.4-positive material. The scale indicates $155 \mu \mathrm{m}$, which is the length of the side of a pixel. B Section incubated with diluent (control). No staining is seen

moderately heterogeneous. Examples of the results of the quantitative autoradiographic analysis for the two doses are presented in Fig. 2A, B. The number of animals employed in the initial pilot study with 5-, 50- and 500- $\mu \mathrm{g}$ dose groups $(n=4,5)$ was too small to achieve statistical significance; however, the results from this feasibility study did suggest that the $\mathrm{CV}$ of the activity levels obtained in autoradiographs from tumors treated with $500 \mu \mathrm{g}$ $(0.289 \pm 0.06 \mathrm{SEM})$ was much smaller than in either the 5 - or 50- $\mu$ g groups. The differences between the $\mathrm{CV}$ of the 5 - and 50- $\mu$ g groups, although not necessarily unworthy of future investigation, were not felt to be significant $(0.401 \pm 0.04$ and $0.501 \pm 0.05$ respectively), especially considering the variability within each group. Therefore, in 

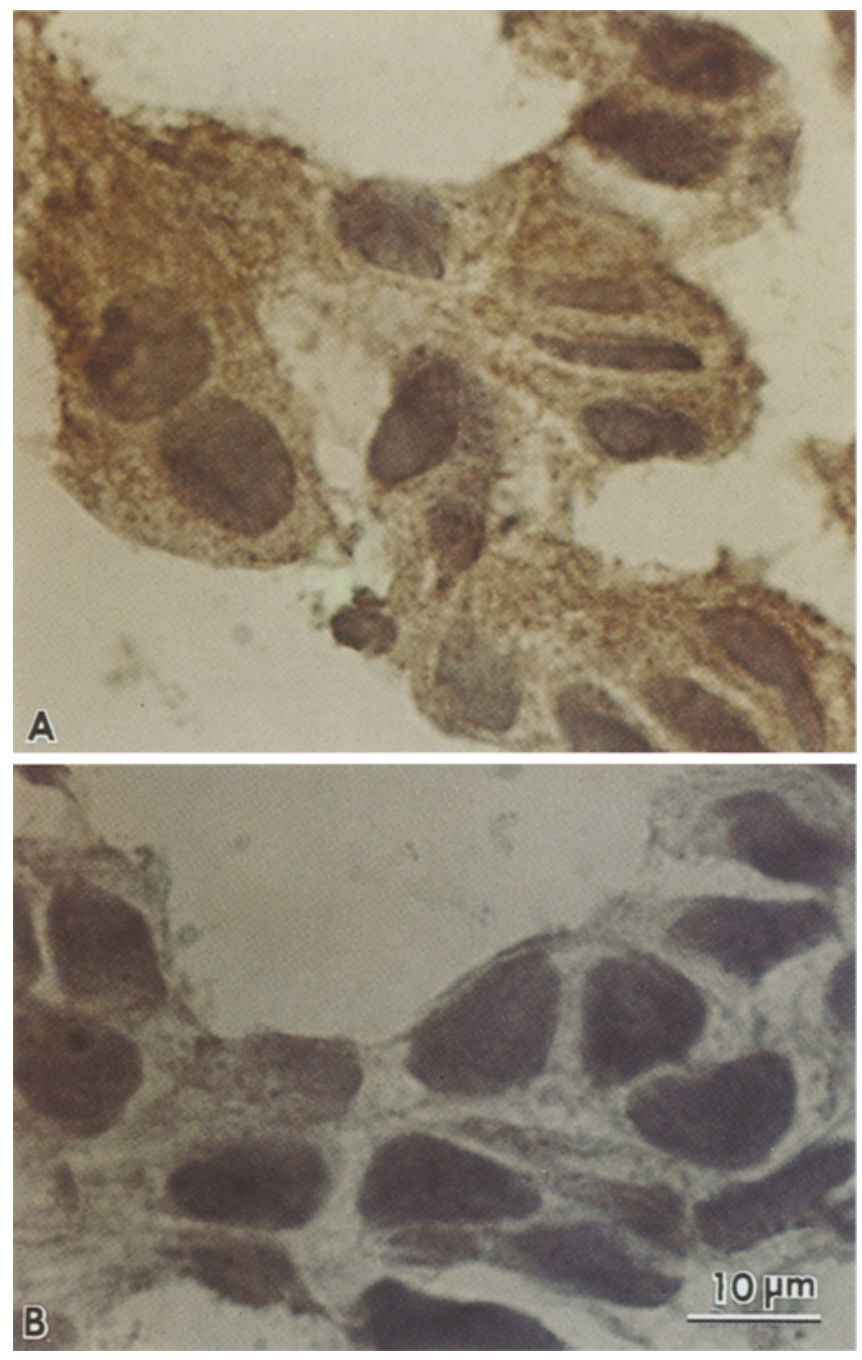

Fig. 4A, B. Micrographs of tumor cells from xenograft stained with 5G6.4. $(1250 \times)$ A Stained granules are seen in the cytoplasm and are concentrated along the membranes of the cells. B Cells in a control section. No staining is seen

the definitive study we expanded the number of animals in the $5-\mu \mathrm{g}$ and $500-\mu \mathrm{g}$ groups to $11-13$ /group for further evaluation. The uniformity of radioantibody distribution in the $500-\mu \mathrm{g}$ protein dose group was substantially greater than in the 5- $\mu$ g protein dose group at the 6-day time point after injection. This relatively long time after injection was chosen, as at this time tumor-specific binding predominates [32]. The mean $\mathrm{CV}$ of the activity levels of the autoradiographs from the $500-\mu \mathrm{g}$ group was $0.327 \pm 0.027$ and that of the $5-\mu \mathrm{g}$ group was $0.458 \pm 0.044(P=0.0078)$ $(P<0.01)$ (Table 1$)$. These results provide strong support for our hypothesis that a more uniform intratumoral distribution of antibody is achieved when higher protein doses are administered.

Changing the protein dose from $5 \mu \mathrm{g}$ to $500 \mu \mathrm{g}$ did not significantly affect the fraction of the injected dose reaching the tumor. However, increased amounts of radioactivity were found in the normal tissues at the higher doses, probably because of higher blood levels (Table 2). As a result, tumor to normal tissue ratios of delivered radioac-
Table 1. The CV of the in vivo intratumoral distribution of ${ }^{125} \mathrm{I}-5 \mathrm{G} 6.4$ activity $^{\mathrm{a}}$

\begin{tabular}{ll}
\hline CV for protein dose of & \\
\hline $5 \mu \mathrm{g}(n=11)$ & $500 \mathrm{mg}(n=13)$ \\
\hline 0.302 & 0.266 \\
0.332 & 0.456 \\
0.537 & 0.188 \\
0.300 & 0.292 \\
0.436 & 0.283 \\
0.484 & 0.209 \\
0.827 & 0.347 \\
0.482 & 0.380 \\
0.410 & 0.235 \\
0.419 & 0.351 \\
0.504 & 0.307 \\
& 0.461 \\
& 0.476 \\
\hline $0.458 \pm .044$ & $0.327 \pm .027$ \\
mean \pm SEM & mean \pm SEM \\
\hline The values were obtained from serial sections from each tumor \\
a Coefficient of variation of individual tumors. CV at both protein dose \\
levels demonstrate some overlap, yet as a group, significantly lower \\
values were seen at the higher protein dose. The lower CV indicates more \\
homogeneous antibody distribution at the high protein dose
\end{tabular}

tivity were significantly lower at the $500-\mu \mathrm{g}$ level than at the 5- $\mu \mathrm{g}$ level $(P<0.05)$. Tumor size was not found to be a factor affecting the intratumoral distribution in this study, there being no correlation between the $\mathrm{CV}$ values of the intratumoral radioactivity and the tumor weights. The mean tumor weights were comparable between the groups: $5 \mu \mathrm{g}, 0.971 \pm 0.206 \mathrm{~g} ; 500 \mu \mathrm{g}, 0.885 \pm 0.199 \mathrm{~g}$.

\section{Discussion}

Our study quantitatively determined the effect of antibody protein dose on overall and intratumoral distribution of 125I-5G6.4 monoclonal antibody in nude mice with human ovarian carcinoma xenografts 6 days after injection. Our study differs from prior theoretical and qualitative studies in that we applied this quantitative imaging method to assess this question objectively $[2,8,19]$ in large groups of animals with multiple sequential sections from each tumor, so that over 240 different tumor sections were quantitatively assessed. With this quantitative method, we have been able to demonstrate that increasing the protein dose from $5 \mu \mathrm{g}$ to $500 \mu \mathrm{g}$ in this system significantly increases the uniformity of intratumoral distribution of antibody. The quantitative approach removes any potential subconscious or conscious observer bias in the interpretation of qualitative studies. Our study further demonstrates that this increased uniformity comes with a price of a decrease in target to background ratios.

Our quantitative results are somewhat similar to those recently reported by Blumenthal and colleagues, in which two different monoclonal antibodies reactive with carcinoembryonic antigen were qualitatively shown to have a more uniform intratumoral distribution when a high pro- 
Table 2. Biodistribution of ${ }^{125} \mathrm{I}-5 \mathrm{G} 6.4$

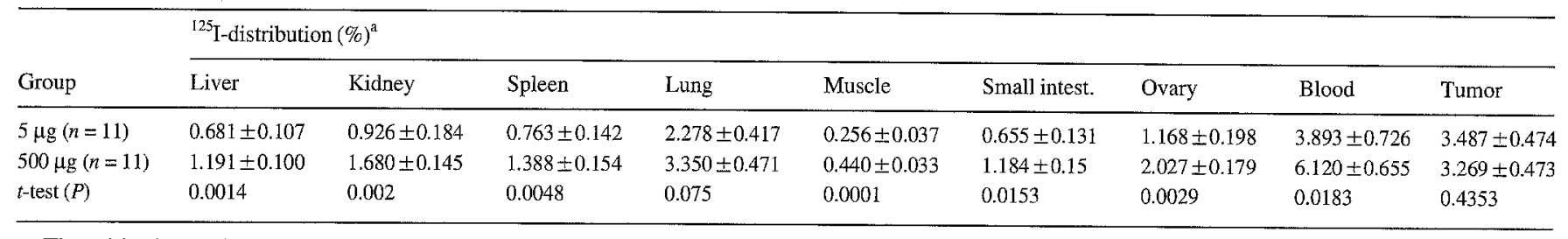

a The table shows the mean percentage injected dose per gram tissue \pm standard error of mean (SEM), of radioantibody reaching normal tissue and tumor in each group and reveals higher uptake of radiolabeled

antibody, $5 \mathrm{G} 6.4$, at the 500- $\mu \mathrm{g}$ injected protein dose in the normal tissues at sacrifice. No significant difference was found between the two groups in the amount of dose reaching the subcutaneous tumor xenografts

tein dose rather than a low dose was used [2]. These investigators, however, were unable to demonstrate improved intratumoral uniformity of uptake with higher protein doses of a nonspecific antibody where uniform uptake was seen, even with a low protein dose and for a specific antibody that targeted tumor less well than with their best reagents. The improved homogeneity in intratumoral uptake of radioantibody we demonstrated, even with relatively low target to background ratios, indicates that protein dose may have a substantial effect on targeting at the microscopic level, even in systems where antibody targeting is not optimal.

It is likely that the lower tumor to normal organ ratios seen in our animals at high protein doses were due to partial or complete accessible tumor antigenic saturation at the 500- $\mu \mathrm{g}$ dose. Of note, however, is that our percentage injected dose per gram in the tumor did not actually fall at higher protein doses, rather the percentage uptake in normal tissues increased. It is thus possible that a component of the decrement in target to background ratios at the high protein dose was due to higher blood levels of radioactivity in the high-protein dose group because of the genetic background of the nude mice (Swiss) that were used and the IgG2a isotype of the $5 \mathrm{G} 6.4$ antibody.

Rapid blood clearance of IgG2a monoclonal antibodies when low protein doses $(<100 \mu \mathrm{g})$ are given to nude mice has been reported [25]. This is probably because mouse IgG2a are selectively cleared by the liver and spleen in these animals. Higher protein doses $(>100 \mu \mathrm{g})$ were reported to block the rapid clearance of $\operatorname{IgG} 2 \mathrm{a}$ and result in higher blood radioantibody levels [25]. Higher blood radioantibody levels logically can result in higher delivery of antibody to normal tissues. We did not observe (at the 6-day time point we examined), an increase in splenic or hepatic radioactivity in the low protein dose group compared to the higher protein dose group. Six days post-injection may not be the optimal time to detect increased $125 \mathrm{I}$ uptake in the liver and spleen, however. At this late time, dehalogenation of antibody may have occurred, particularly in the liver, which could mask increased targeting to these structures.

It is possible that antibody cross-reactivity with low levels of circulating antigen and attendant rapid clearance of antibody antigen complexes could have occurred at our lower protein doses, which were largely blocked at the high protein dose. We have, however, not been able to demonstrate circulating antigen in this system (Wahl et al. unpublished data) and we do not believe this latter suggestion explains our findings.
Our in vivo data, showing improved homogeneity of tumor uptake, are parallel to in vivo results and also similar to in vitro data reported by Kwok, who used multicellular spheroids and showed that tumor antigenic sites were saturable $[2,17]$. It has, however, been somewhat difficult to demonstrate tumor saturation in vivo. Indeed, prior studies by ourselves in another antibody/tumor system showed no clear change in the percentage injected dose per gram of iodinated intact antibody reaching tumors in a melanoma xenograft system at protein doses ranging from $6.25 \mu \mathrm{g}$ to $1.875 \mathrm{mg}$ 125 I-labeled 225.285 or $763.24 \mathrm{~T}$ monoclonal anti-melanoma monoclonal antibodies [30].

Increasing the antibody protein dose from $0.001 \mathrm{mg}$ to $1.0 \mathrm{mg}$ did not improve tumor to normal tissue ratios nor improve external scintigraphic contrast of human colonic cancer xenografts on hamsters [24]. More recent studies, however, were performed in a nude mouse where the animal weight was substantially lower and tumor saturation could, and was, more easily accomplished [2]. Only slightly increased levels of 131I-labeled antibody reached murine lymphomas at progressively higher protein doses [1]. A decline in fractional anti-(colorectal cancer) monoclonal antibody uptake to colon cancer xenografts in hamsters at protein doses above $100 \mu \mathrm{g}$ was seen in another study, but full tumor saturation was not achieved at this dose [6].

These data indicate that, in selected animal models, some element of tumor saturation is possible with high doses of antibody protein, though very high protein levels are generally required. Thus, our quantitative experimental results partially support antibody localization models and concepts previously outlined by several groups $[2,8,9,12$, $13,17,19,26]$. These concepts suggest that higher protein doses should improve the uniformity of antibody distribution in tumors and result in increased penetration of antibody away from blood vessels into tumors. We did not, however, observe substantial difficulty in permeating the central portions of our tumor xenografts with antibody. Certainly, additional studies with antibody fragments and at other time points would be useful to address whether better penetration is possible, as has been suggested in theoretical and initial qualitative autoradiographic studies $[8,21]$.

The implications of uniform distribution of radioactivity within a tumor are somewhat dependent on the choice of radionuclide for tumor therapy $[10,16]$. If a low protein dose of antibody is used, it would appear from our study and others that much of the antibody molecule will bind to tumor-associated antigen located near the vessels that enter 
the tumor. With higher protein doses, greater diffusion seems to be achievable. This latter more homogeneous distribution would probably be necessary for treatment with low-energy $\beta$ particles or $\alpha$ particles, or drug-antibody conjugates, to be successful. For therapy with more energetic $\beta$ emitters, such as ytterium-90, a less uniform distribution of radiopharmaceuticals in tumors may be acceptable $[10,16]$. For tumor imaging, high-level localization of antibody to the tumor would be necessary, while uniform distribution of radioactivity within the tumor would be less essential. Thus, lower protein doses may be perfectly appropriate for tumor imaging and may offer advantages over higher protein doses.

The precise degree of homogeneous intratumoral radioactivity distribution of antibody conjugates required for therapeutic efficacy remains to be determined. Quantitative autoradiographic studies such as ours may be helpful in addressing this issue.

\section{In summary}

Our study demonstrates that, in a human ovarian carcinoma xenograft system in nude mice, a relatively low protein dose $(5 \mu \mathrm{g})$ of radiolabeled antibody results in significantly superior targeting compared to a higher $(500 \mu \mathrm{g})$ protein dose. The higher protein dose, however, results in a significantly more uniform distribution of radioactivity within the tumor than the lower dose. Thus, an optimal protein dose, at least in this animal system, may exist for therapy while another optimal protein dose may exist for imaging. Additional quantitative studies in other animal models and patients, which address this issue, will be of interest.

\section{References}

1. Badger CC, Krohn KA, Shulman H, Flournoy N, Bernstein ID (1986) Experimental radioimmunotherapy of murine lymphoma with 131I-labeled anti-T-cell antibodies. Cancer Res 46: 6223-6228

2. Blumenthal RD, Fand I, Sharkey RM, Boerman OC, Kashi R, Goldenberg DM (1991) The effect of antibody protein dose on the uniformity of tumor distribution of radioantibodies: an autoradiographic study. Cancer Immunol Immunother 33: 351-358

3. Bradford M (1976) A rapid and sensitive method for the quantitation of microgram quantities of protein utilizing the principle of proteindye binding. Anal Biochem 72: 248-255

4. del Rosario RB, Baron LE, Lawton RG, Wahl RL (1992) Streptavidin-biotinylated IgG conjugates: a simple procedure for reducing polymer formation. Technical note. Nucl Med Biol 19: 417-421

5. Esteban JM, Schlom J, Mornex F, Colcher D (1987) Radioimmunotherapy of athymic mice bearing human colon carcinomas with monoclonal antibody B72.3: histological and autoradiographic study of effects on tumors and normal organs. Eur J Cancer Clin Oncol 23: $643-655$

6. Fenwick JR, Philpott GW, Connett JM (1989) Biodistribution and histological localization of anti-human colon cancer monoclonal antibody (MAb) 1A3: the influence of administered MAb dose on tumor uptake. Int J Cancer 44: 1017-1027

7. Fraker PJ, Speck JC (1978) Protein and cell membrane iodinations with a sparingly soluble chloroamide, 1,3,4,6-tetrachloro-3L,6Ldiphenylglycoluril. Biochem Biophys Res Commun 80: 849-857

8. Fujimori K, Covell DG, Fletcher JE, Weinstein JN (1989) Modeling analysis of the global and microscopic distribution of immunoglobulin $\mathrm{G}, \mathrm{F}\left(\mathrm{ab}^{\prime}\right) 2$, and $\mathrm{Fab}$ in tumors. Cancer Res $15 ; 49: 5656-5663$
9. Fujimori K, Fisher DR, Weinstein JN (1991) Integrated microscopicmacroscopic pharmacology of monoclonal antibody radioconjugates: The radiation dose distribution. Cancer Res 15; 51: $4821-4827$

10. Griffith MH, Yorke ED, Wessels BW, DeNardo GL, Neacy WP (1988) Direct dose confirmation of quantitative autoradiography with micro-TLD measurements for radioimmunotherapy. J Nucl Med 29: 1795-1809

11. Hsu SM, Raine L, Fanger H (1981) Use of avidin-biotin-peroxidase complex $(\mathrm{ABC})$ in immunoperoxidase techniques: comparison between $\mathrm{ABC}$ and unlabeled antibody (PAP) procedures. J Histochem Cytochem 29: 577-580

12. Jain RK (1989) Delivery of novel therapeutic agents in tumors: physiological barriers and strategies. J Natl Cancer Inst 81: 570-576

13. Jain RK (1990) Physiological barriers to delivery of monoclonal antibodies and other macromolecules in tumors. Cancer Res [Suppl] 50: $814 \mathrm{~s}-819 \mathrm{~s}$

14. Joftes DL (1963) Radioautography, principles and procedures. J Nucl Med 4: 143-154

15. Key ME, Bernhard MI, Hoyer LC, Foon KA, Oldham RK, Hanna MG (1983) Guinea pig line 10 hepatocarcinoma model for monoclonal antibody serotherapy: in vivo localization of a monoclonal antibody in normal and malignant tissues. J Immunol 130: $1451-1457$

16. Koral KF, Kwok CS, Yang FE, Wahl RL (1989) Variations in absorbed dose for radiolabeled monoclonal antibodies in a murine human-tumor xenograft. J Nucl Med 30: 777

17. Kwok CS, Cole SE, Liao SK (1988) Uptake kinetics of monoclonal antibodies by human malignant melanoma multicell spheroids. Cancer Res 48: 1856-1863

18. Moshakis V, McIlhinney RA, Neville AM (1981) Cellular distribution of monoclonal antibody in human tumours after I. V. administration. Br J Cancer 44: 663-669

19. Ong GL, Mattes MJ (1989) Penetration and binding of antibodies in experimental human solid tumors grown in mice. Cancer Res 1;49: 4264-4273

20. Patt YZ, Lamki LM, Haynie TP, Unger MW, Rosenblum MG, Shirkhoda A, Murray JL (1988) Improved tumor localization with increasing dose of indium 1 11-labeled anti-carcinoembryonic antigen monoclonal antibody ZCE-025 in metastatic colorectal cancer. J Clin Oncol 6: $1220-1230$

21. Pervez S, Epenetos AA, Moor WJ, Evans DJ, Rowlinson G, Dhokia B, Krausz T (1988) Localization of monoclonal antibody AUAl and its $F\left(a b^{\prime}\right) 2$ fragments in human tumour xenografts: an autoradiographic and immunohistochemical study. Int J Cancer [Suppl] 3 $23-29$

22. Sands H, Jones PL, Shah SA, Palme D, Vessella RL, Gallagher BM (1988) Correlation of vascular permeability and blood flow with monoclonal antibody uptake by human Clouser and renal cell xenografts. Cancer Res 48: 188-193

23. Schroff RW, Woodhouse CS, Foon KA, Oldham RK, Farrell MM, Klein RA, Morgan AC Jr (1985) Intratumoral localization of monoclonal antibody in patients with melanoma treated with antibody to a 250,000-dalton melanoma-associated antigen. J Natl Cancer Inst 74: 299-306

24. Sharkey RM, Primus FJ, Goldenberg DM (1987) Antibody protein dose and radioimmunodetection of GW-39 human colon tumor xenografts. Int J Cancer 39: 611-617

25. Sharkey RM, Natale A, Goldenberg DM, Mattes MJ (1991) Rapid blood clearance of immunoglobulin $\mathrm{G} 2 \mathrm{a}$ and immunoglobulin $\mathrm{G} 2 \mathrm{~b}$ in nude mice. Cancer Res 15; 51: 3102-3107

26. Thomas GD, Chappell MJ, Dykes PW, Ramsden DB, Godfrey KR, Ellis JRM, Bradwell AR (1989) Effect of dose, molecular size, and protein binding on tumor uptake of antibody or ligand: a biomathematical model. Cancer Res 49:3290

27. Wahl RL (1989) Radiolabeled monoclonal antibody imaging. Radiol Rep 1: $347-361$

28. Wahl RL, Philpott GW, Parker CW (1983) Monoclonal antibody radioimmunodetection of human-derived colon cancer. Invest Radiol 18: $58-62$ 
29. Wahl RL, Sherman P, Fisher S (1984) The effect of specimen processing on radiolabeled monoclonal antibody biodistribution. Eur J Nucl Med 9: 382-384

30. Wahl RL, Liebert M, Wilson BS (1986) The influence of monoclonal antibody dose on tumor uptake of radiolabeled antibody. Cancer Drug Deliv 3: 243-249

31. Wahl RL, Liebert M, Biesman B, Roberts J, Jackson G, Kronberg S, Laino L (1986) Production and characterization of a murine monoclonal antibody reactive with ovarian and other epithelial carcinomas. Proc Am Assoc Cancer Res 27: 355

32. Wahl RL, Barrett J, Geatti O, Liebert M, Wilson BS, Fisher S, Wagner JG (1988) The intraperitoneal delivery of radiolabeled monoclonal antibodies: studies on the regional delivery advantage. Cancer Immunol Immunother 26: 187-201
33. Wahl RL, Wissing J, del Rosario R, Zasadny KR (1990) Inhibition of autoradiolysis of radiolabeled monoclonal antibodies by cryopreservation. J Nucl Med 31: $84-89$

34. Yang F, Brown RS, Koral KF, Jackson G, Clavo A, Wahl RL (1989) Quantitative autoradiographic evaluation of the influence of antibody protein dose on antibody distribution in human tumor xenografts. J Nucl Med 30: 759

35. Yonekura Y, Brill AB, Som P, Bennett GW, Fand I (1983) Quantitative autoradiography with radiopharmaceuticals, part I: digital filmanalysis system by videodensitometry: concise communication. J Nucl. Med 23: 231-237 